\title{
Barriers, Strategies, and Resources to Thriving School Gardens
}

\author{
Amy Hoover, $\mathrm{MS}^{1}$; Sarvenaz Vandyousefi, $\mathrm{PhD}, \mathrm{RD}^{2}$; Bonnie Martin, $\mathrm{BA}^{1}$; \\ Katie Nikah, $\mathrm{MPH}^{1}$; Michele Hockett Cooper, $\mathrm{MS}^{1}$; Anne Muller, BA ${ }^{3}$; Edwin Marty, $\mathrm{BA}^{4}$; \\ Marissa Duswalt-Epstein, MBA, RD ${ }^{1}$; Marissa Burgermaster, PhD, $\mathrm{RD}^{1,5}$; \\ Lyndsey Waugh, $\mathrm{BA}^{6}$; Brie Linkenhoker, $\mathrm{PhD}^{7}$; Jaimie N. Davis, PhD, $\mathrm{RD}^{1}$
}

\begin{abstract}
Objective: To identify school garden attributes and practices that most strongly contribute to garden use and sustainability and translate them into recommendations for improving garden-based nutrition education.

Design: Surveys were developed and administered to school stakeholders to assess the barriers, strategies, and resources for successful school garden-based nutrition education. A panel of school garden experts identified thriving school gardens. Logistic regression was used to identify which attributes predicted thriving school garden programs.

Setting: Approximately 109 schools across Greater Austin, TX.

Participants: A total of 523 school teachers and 174 administrators.

Outcomes: Barriers, strategies, and resources relevant to successful school gardening nutrition programs.

Results: Thriving school gardens were 3-fold more likely to have funding and community partner use $(P=0.022$ and $P=0.024), 4$ times more likely to have active garden committees $(P=0.021)$, available garden curriculum $(P=0.003)$, teacher training $(P=0.045), \geq 100$ students who used the garden annually $(P=0.047)$, and 12 times more likely to have adequate district and administrator support $(P=0.018)$.

Conclusions and Implications: Adequate administrative and district support is fundamental when implementing a school garden. Schools may benefit from finding additional funding, providing teacher garden training, providing garden curriculum, forming garden leadership committees, and partnering with local community organizations to improve garden-based nutrition education.
\end{abstract}

Key Words: school gardens, sustainability, nutrition education, school stakeholders (J Nutr Educ Behav. 2021;53:591-601.)

Accepted February 25, 2021. Published online April 25, 2021.

\section{INTRODUCTION}

School gardening programs are increasingly used to promote health

\footnotetext{
${ }^{1}$ Department of Nutritional Sciences, University of Texas at Austin, Austin, TX

${ }^{2}$ Department of Pediatrics, Division of General Pediatrics, New York University School of Medicine and Bellevue Hospital Center, New York, NY

${ }^{3}$ Austin Independent School District, Austin, TX

${ }^{4}$ City of Austin Office of Sustainability, Austin, TX

${ }^{5}$ Department of Population Health, Dell Medical School, University of Texas at Austin, Austin, TX

${ }^{6}$ Sprouts Healthy Communities Foundation, Phoenix, AZ

${ }^{7}$ Worldview Studio, Menlo Park, CA

Conflict of Interest Disclosure: The authors have not stated any conflicts of interest.

Address for correspondence: Jaimie N. Davis, PhD, Department of Nutritional Sciences, University of Texas at Austin, 1400 Barbara Jordan Blvd, Austin, TX 78723.; E-mail: Jaimie. davis@austin.utexas.edu

(C) 2021 The Authors. Published by Elsevier Inc. on behalf of Society for Nutrition Education and Behavior. This is an open access article under the CC BY-NC-ND license (http:// creativecommons.org/licenses/by-nc-nd/4.0/)

https://doi.org/10.1016/j.jneb.2021.02.011
}

that school gardens can improve dietary intake and dietary-related psychosocial variables in children. ${ }^{2-6}$ Public schools are the ideal place to reach the 23.9 million kindergarteners through fifth-grade children in the US. ${ }^{7}$ Currently, 40 states $-78 \%$ of the nation-require nutrition education for all students, ${ }^{8}$ yet only 15 states' explicitly address teacher professional development for nutrition education. This disparity means that most teachers in the US are mandated to teach nutrition education with little or no training. Texas Education Code, Section 38.014, ${ }^{9}$ mandates schools in Texas to implement prevention programs that include nutrition instruction, as well as health and physical education.

School garden programs provide ideal opportunities to meet these nutrition mandates and have 
consistently been shown to improve nutrition and health in children. $6,10,11$ However, little is known on how to maintain and sustain successful school garden programs, and this is a growing concern for school stakeholders. ${ }^{12,13}$ A few studies have evaluated school gardening programs to identify barriers to garden maintenance and predicting factors contributing to sustainability. Pervasive challenges included the lack of centralized organization, ${ }^{12,14}$ materials and resources, $^{12,15,16}$ consistent maintenance, ${ }^{17}$ and general interest. ${ }^{12}$ In contrast, a strong community support network, ${ }^{18,19}$ paid garden coordinator with management responsibilities, ${ }^{20}$ integrated curriculum, ${ }^{14}$ and established funding ${ }^{13,17}$ were key strategies for sustaining school garden programs. Burt et $\mathrm{al}^{14}$ surveyed 99 school gardeners (including teachers, administrators, parents, and garden educators) primarily from New York State and Washington, DC areas, and found that time, staff, funding, curriculum, and space were the greatest barriers sustaining their school gardens. ${ }^{12}$ Although numerous studies have identified the health benefits of school gardens, the barriers and strategies used to sustain school gardens are still unclear and warrant further investigation. Thus, the goal of this study is to identify school garden attributes and practices that most strongly contribute to garden use and sustainability and translate them into recommendations for improving garden-based nutrition education.

\section{METHODS}

\section{Study Design}

This was a cross-sectional study in which the authors developed and administered a survey for school stakeholders. Two surveys were developed and pilot-tested, 1 for the administrators and 1 for school teachers. A garden observation log was also developed. The revised surveys were then administered to teachers and administrators across the Greater Austin area. A panel of school garden experts identified the school gardens that were thriving on the basis of physical characteristics, teacher and student usage, and integration into the school culture.

Approval was obtained from The University of Texas's Institutional Review Board and by each independent school district.

\section{Survey Development}

The Ozer conceptual model was used to guide the development of the survey. Ozer ${ }^{21}$ developed a conceptual model, on the basis of the social ecological-transactional model, that shows how school gardens are effective educational tools to improve child health. This model treats the child as nested within immediate contexts or microsystems (eg, school, family, community) that reciprocally interact with each other and the child over time to shape development and behaviors.

An environmental scan of the existing literature, including the Portland School Garden Assessment study survey and GREEN (garden resources, education, and environment nexus) tool, ${ }^{22}$ were used to develop 2 versions of a survey, 1 version for school administrators and 1 version for school teachers. The survey questions fell into the 4 domains, established from the GREEN tool developed by Burt et al. ${ }^{22}$ Domain A: Resources and Support metrics consisted of those measuring support and resources given to the school garden that supports its use and sustainability. Domain B: Physical Garden reflected physical attributes of the garden, including physical maintenance plans and harvest uses. Domain C: Student Experience consisted of how often students use the garden, how often teachers teach in the garden, courses taught in the garden, and available and/or use of the garden curriculum. Domain D: School Community refered to volunteer and/or parent support and availability of teacher training. The survey also included some qualitative questions on how administrators and/or districts supported the school gardens and how they could be more supportive, as well as open responses to capture additional resources received and garden usages. The survey also included a fifth domain that asked school stakeholders to identify barriers that hindered garden use by school staff.

A panel of experts represented the City of Austin Office of Sustainability, the Sustainable Food Center, Austin Independent School District, and the University of Texas was assembled to assess content validity. Specifically, the panel of experts was asked to assess content validity and determine if the questions were clear and easy, covered all the strategies, barriers, and resources needed for school gardens, and whether or not certain questions were missing or needing to be expanded. Many open-ended responses were included in these initial versions.

With feedback from the panel of experts and existing literature, a garden observation log was developed to evaluate the garden space, which examines physical features such as number and types of garden beds, types of materials used for the construction of beds, square footage of the entire garden, and location and type of water sources. The observation log also included photographs of the physical garden.

In Fall 2016 and Spring 2017, the surveys were pilot-tested with 16 administrators and 80 school teachers from 16 different elementary schools. A \$5.00 gift card incentive was given to each participant on return of a completed survey. Data collection was conducted by undergraduate students at the University of Texas, satisfying course credit. Construct validity was assessed using principal component analysis. ${ }^{23,24}$ Separate principal component analyses of the 5 final constructs showed that each of them had, as intended, a single construct with an eigenvalue greater than 1, accounting for $83 \%-97 \%$ of the variance across the 5 constructs. The Kaiser-Meyer-Olkin Measure of Sampling was $0.546(P<0.001)$. The standardized covariances between latent constructs were 0.602 (Resources and Support), 0.532 (Physical Garden), and 0.633 (Student Experience), 0.510 (School Community), and 0.644 (Barriers).

On the basis of responses from the pilot study, minimal revisions were made to the survey, with the main change being open-ended responses were changed to multiple-choice 
options. In addition, the photographs and observation logs revealed that more questions on the physical garden observation log were required. Final surveys included 21 questions for the administrator and teacher version and 23 questions for the garden observation log. Supplementary Table 1 displays the survey questions and responses, and Supplementary Table 2 includes the garden observation $\log$.

\section{Recruitment and Enrollment}

The Sustainable Food Center provided a list of 216 schools across the Austin area with physical gardens, which included any type of garden (native, herb, or vegetable). A total of 150 of these schools were contacted, 110 of which agreed to complete the surveys. Consent forms were required from each principal to allow school participation, as well as individual consent forms from each participant, allowing anonymous use of their responses. Research personnel from the University of Texas or the administrator at the school presented a brief overview of this project and expectations at a faculty meeting and then distributed surveys to volunteer participants. In some cases, no presentation was given, and the school administrator emailed their faculty about the project and asked teachers to complete the surveys voluntarily.

Both administrators and teachers were asked to respond to surveys regarding their school garden using either paper surveys or electronic surveys via the Qualtrics (Provo, UT, 2017) platform. Teachers were eligible to participate in this study if they had some involvement with their school garden, including those that were actively teaching in the garden or part of the garden leadership team. Research personnel picked up the completed paper surveys from participating schools, completed the garden observation logs, and took photographs of the school gardens. Teachers who completed the surveys (via paper or online) were awarded a \$5.00 gift card incentive for their participation.

\section{School Garden Expert Panel}

A panel of 10 experts who worked extensively with school gardens across the Greater Austin area was formed to assist with this project. An electronic list of the schools included in the analytic sample was shared with each panel member. Each expert was asked to identify school gardens with which they were familiar as thriving on the basis of physical appearance; upkeep; and teacher, student, and community usage and integration of the school garden. The experts completed this electronic assessment individually, and responses were not shared among the panel to avoid groupthink bias. Experts were only asked to comment on schools they had directly worked with in the past 3 years. Thriving school gardens were coded if 1 or more experts identified them as such.

\section{Statistical Analysis}

Descriptive statistics and graphical analyses were used to examine the frequencies and distributions of data. The $t$ tests were completed between surveys with missing and no-missing responses, and data were determined to be missing at random. Logistic regression analyses were conducted to assess factors associated with thriving ratings of the school gardens. $A$ priori covariates were determined by examination of the literature to assess which variables may influence school garden implementation ${ }^{20,21}$ and included school districts, free and reduced lunch status, and ethnicity or race of students, which were obtained from the school level registration data listed on their websites. All analytical procedures were performed using SPSS (version 25, IBM, 2017), with a 0.05 alpha level as the criterion for statistical significance.

\section{RESULTS}

\section{School Demographics}

Complete data were obtained from 109 schools, the majority of them being elementary level, spread across 8 independent school districts in Greater Austin, TX (Table 1). The population size of the schools averaged around 600 students with a range of 53 to 3,125 students. Although both low-income and middle and/or high-income schools with multiethnic populations were included in this study, $63 \%$ of the schools served populations that were eligible for free and reduced lunch, and $61 \%$ of the school's population were of Hispanic origin.

\section{Physical Garden Characteristics}

Ninety-three percent of gardens were located a short walk from the school building, and $69 \%$ of school gardens offered some type of seating.

\section{Table 1. Demographics of Schools With School Gardens $(n=109)$}

$\begin{array}{lc}\text { Demographics } & \text { Mean } \pm \text { SD or } \mathbf{n}(\%) \\ \text { Type } & \\ \quad \text { Prekindergarten } & 11(10) \\ \text { Elementary school } & 74(68) \\ \text { Middle school } & 11(10) \\ \quad \text { High school } & 13(12) \\ \text { Districts surveyed, } \mathrm{n} & 8 \\ \text { Free and reduced lunch, \% } & 62.8 \pm 33.2 \\ \text { Ethnicity/race, \% } & \\ \quad \text { Hispanic } & 61.0 \pm 26.0 \\ \quad \text { Non-Hispanic Black } & 9.0 \pm 8.2 \\ \quad \text { Non-Hispanic White } & 22.9 \pm 24.1 \\ \quad \text { Asian } & 3.6 \pm 4.5 \\ \quad \text { Other } & 3.5 \pm 2.3 \\ \text { Teachers who completed the survey, } n & 523 \\ \text { Teachers who completed the survey per school } & 4.8 \pm 3.1 \\ \text { Administrators who completed the survey, } \mathrm{n} & 174 \\ \text { Administrators who completed the survey per school } & 1.6 \pm 0.8 \\ \text { Student population size } & 602.1 \pm 440.1\end{array}$


Table 2. Physical Garden Characteristics of School Gardens ( $n=109)$

\begin{tabular}{|c|c|}
\hline Characteristic & Mean \pm SD (range) or $n(\%)$ \\
\hline Size of garden, sq ft & $783.6 \pm 1,817.5(10.0-12,000.0)$ \\
\hline Garden age, y & $2.2 \pm 1.4(0.2-20.0)$ \\
\hline \multicolumn{2}{|l|}{ No. of beds } \\
\hline 1 & $13(12)$ \\
\hline 2 & $23(21)$ \\
\hline 3 & $43(39)$ \\
\hline 4 & $19(17)$ \\
\hline 5 & $12(11)$ \\
\hline \multicolumn{2}{|l|}{ Type of beds/plants } \\
\hline Vegetable & $89(82)$ \\
\hline Fruit trees & $32(29)$ \\
\hline Native & $95(87)$ \\
\hline Rain & $20(18)$ \\
\hline Herb & $81(74)$ \\
\hline Seating available & $76(69)$ \\
\hline Shade covered & $27(36)$ \\
\hline Not shade covered & $48(63)$ \\
\hline \multicolumn{2}{|l|}{ Walking distance from the school } \\
\hline Short walk ( $\leq 5 \mathrm{~min})$ & $101(93)$ \\
\hline Long walk (> 5 min) & $8(7)$ \\
\hline Wheelchair accessible & $54(50)$ \\
\hline Compost bin & $49(45)$ \\
\hline Garden protected with fence or barrier & $56(51)$ \\
\hline \multicolumn{2}{|c|}{ Physical observation of the garden condition } \\
\hline Disrepair or unmaintained & $18(17)$ \\
\hline Somewhat maintained & $41(38)$ \\
\hline Well-maintained & $50(46)$ \\
\hline
\end{tabular}

Approximately $51 \%$ of the gardens were protected by a fence or barrier. Only $36 \%$ of gardens had a covered area to provide shade in their garden (Table 2).

\section{Frequencies of Survey Responses for the First 4 Domains}

The first 4 domains (Table 3) are as follows: (1) Resources and Support, (2) Physical Garden, (3) Student Experience, and (4) School Community.

Domain A: resources and support. The amount of funding was asked on the survey, but this was missing or unknown from $72 \%$ of schools. Of those that did answer the funding question, 9\% reported an annual budget $<\$ 500,6 \%$ reported an annual budget between $\$ 500$ and $\$ 2000$, and 13\% reported an annual budget $>\$ 2,000$. Approximately $65 \%$ of teachers who were surveyed indicated that their garden had administrator support. Twenty-eight percent of the schools had a garden committee that managed the garden at their school. Fifty-five percent of schools had a person designated as the garden coordinator. Of those schools, only $11 \%$ had a garden coordinator who held a paid position. The majority of garden coordinators were teachers, with parents being the second most common. Thirty-eight percent of schools had a partner organization that used and helped with the garden.

Domain B: physical garden. Eightyfive percent of schools surveyed perceived themselves as having either a somewhat or well-maintained garden. Fifty-seven percent of the schools reported hosting garden workdays throughout the year, with 1 or 2 garden workdays per year being the most common. Approximately $80 \%$ of respondents selected that the harvest was used as part of the curriculum, and approximately 40\% of respondents reported that the harvest was used in the community and/ or given to families.

Domain C: student experience. In the surveyed population that averages 602 students per school, 55\% of the schools reported less than 50 students used the garden annually. Regarding the frequency of teaching in the school garden, $45 \%$ of teachers taught weekly in the garden. Eightysix percent of schools surveyed used the garden for teaching core courses. In addition, $73 \%$ of schools taught at least 1 noncore course in the garden. Only $28 \%$ of schools used a specific garden curriculum.

Domain D: school community. Fiftyfour percent of schools had a volunteer or parental support in the garden. Of the schools reporting volunteer garden support, 1-20 volunteers per year was the most commonly reported number of volunteers, and 1-10 hours per year was the most commonly reported workload. Approximately $68 \%$ of the schools surveyed had teacher training around the school garden.

\section{Barriers}

Figure 1 displays the frequencies of barriers identified by the teachers. The top 3 barriers, reported by more than $50 \%$ of teachers, included: (1) inadequate funding, (2) insufficient administrator and/or district support, and (3) low workdays and community involvement. Figure 2 displays the frequencies of barriers as identified by administrators. The top 3 barriers reported by more than $50 \%$ of administrators included: (1) inadequate teacher involvement, (2) insufficient teacher training, and (3) inadequate funding.

\section{Prediction of Thriving Gardens}

The panel of experts identified 25 schools, or $23 \%$, as thriving on the basis of the physical condition of the garden, school usage of the garden, and integration of the garden into the school community. Table 4 displays the logistic regression analyses of which barriers and strategies predict having a thriving garden. 
Table 3. Survey Responses for all the GREEN Tool Domains

\section{Domains}

Frequencies, n (\%)

Domain A: resources and support

Funding

Missing

$14(13)$

Unknown

$34(31)$

Garden was funded

No funding for the garden

Partner organization that used garden

Missing/unknown

No, partner organizations did not use garden

Yes, partner organizations used garden

No. of organizations that used garden

Missing

1

2

3

4

5

Administrator support

Missing

Unknown

No administrator support

Yes administrator support

Garden coordinator

Missing

None

Unpaid garden coordinator

Paid garden coordinator

Hours that garden coordinator worked, h/wk

Missing

$1-10$

$11-20$

21-40

Garden committee

Unknown

Yes

No

Domain B: physical garden

Missing

Unmaintained

Somewhat maintained

Well-maintained

No. of workdays per year

Missing

$1-2$

$3-10$

$>10$

Harvest use sum

Missing

1

2

$\geq 3$

Harvest use

Missing

Used in cafeteria

Used by community and families
Thriving school gardens were 3-fold more likely to have funding $(\beta=3.51$; 95\% confidence interval $[\mathrm{CI}], 1.20$ -10.26; $P=0.022)$ and a community partner $(\beta=3.01 ; 95 \% \mathrm{CI}, 1.16-7.83$; $P=0.024)$. Thriving school gardens were 4 -fold more likely to have a garden committee $(\beta=4.67 ; 95 \% \mathrm{CI}$, $1.26-17.23 ; P=0.021)$, garden curriculum $(\beta=4.84 ; 95 \%$ CI, $1.73-13.56$; $P=0.003), \quad 100-200$ students who used the garden annually $(\beta=4.53$; 95\% CI, 1.02-20.19; $P=0.047)$, and teacher garden training $(\beta=4.88$; 95\% CI, $1.04-22.95 ; \quad P=0.045)$. Thriving school gardens were 11-fold more likely to have $\geq 201$ students use the garden $(\beta=11.30 ; 95 \% \mathrm{CI}$, 2.39-53.75; $\quad P=0.002)$. Thriving school gardens were 12-fold more likely to have administrator and district support $(\beta=11.98 ; 95 \%$ CI, 1.53 $-9.34 ; P=0.018)$.

\section{DISCUSSION}

Numerous studies have identified the health and academic benefits of school gardens; however, the barriers and strategies used to sustain school gardens are still unclear. This study provides new information identifying barriers, strategies, and attributes that predict having a successful, thriving school garden. The top 7 barriers to having a thriving garden identified in this study were, in order from greatest to least: (1) inadequate administration and district support, (2) low student usage, (3) lack of specific teacher garden training, (4) lack of access to the garden-based curriculum, (5) nonexistent garden committees, (6) inadequate funding, and (7) and lack of community partner use.

Having administrator and district support was fundamental to the success and sustainability of the school garden. Teachers reported that inadequate administrator and district support was the greatest barrier to garden use and integration. The Portland report also found that it was critical for school administrators to encourage teachers to use the garden as part of their instruction. ${ }^{20}$ It is typical for gardens to fail over time when they are taken on by teachers or parents without administrative support, $^{20}$ or when a school gets a new principal who does not set the 
Table 3. (Continued)

\section{Domains}

Frequencies, n (\%)

Used in compost

Used in curriculum

Sold to the community (fundraiser/farmers' market)

Domain C: student experience

Students who used the garden yearly

Missing

$1-50$

$51-100$

$101-200$

$\geq 201$

Teaching amount per year

Missing

$1-2$

$1-2$

Monthly

Weekly

Core courses that were taught in the garden

Missing

None

1

2

3

$>4$

Noncore courses that were taught in garden

Missing

None

1

2

$\geq 3$

Garden curriculum used

Missing

Unknown

No

Yes

$\%$ of grades that used school garden

Missing

$<25 \%$

$25 \%$ to $50 \%$

$51 \%$ to $75 \%$

$76 \%$ to $100 \%$

Domain D: school community

Volunteers and/or parent support

Missing

Unknown

None

Yes

Volunteers per year

Missing

$1-20$

21-50

$\geq 50$

Hours volunteers worked in the garden, h/y

Missing

Unknown

$1-10$ expectation for garden use. There was a qualitative question on the current survey that asked teachers how administrators could be more supportive of the garden. Several suggestions came from that question, including administrators may benefit from encouraging (and possibly incentivize) garden usage by teachers in each grade level. Another potential solution is schools may benefit from planning campus-wide garden-based professional learning opportunities on service days and/or faculty meetings. Another potential solution is that administrators hire staff and/or faculty with outdoor learning in mind. Administrators may benefit from embedding the garden into the school culture, for example, encouraging school-wide events around the garden. The Portland report suggests that administrators establish policies that allow produce to go into the school cafeteria. ${ }^{20}$ Another solution is that districts and administrators provide substitute teachers so that teachers can attend professional development training and/or garden workdays. Forming and fostering partnerships with community and nonprofit groups that want to help in the garden is another potential solution. In addition, setting the perception of the garden as a teaching tool that integrates into the existing classroom curriculum and establishing clear expectations for its use by teachers may change garden usage to become the norm rather than the exception. Administrators supporting, locating, and applying for funding and/or grants and supplying and locating resources for teachers to use in the garden is yet another potential solution.

Having a thriving garden was also linked to having more than 100 students using the garden annually. The data showed that only $18 \%$ of schools had $100+$ students who used the garden annually. These rates are similar to those reported in the Portland study. ${ }^{20}$ This is a relatively low rate of use for a school sample that has such a large population, equating to only 3-5 classes per school using the garden in most schools. Of note, only teachers that were involved in the school garden were surveyed, so these student numbers may be 


\section{Table 3. (Continued)}

$$
\begin{aligned}
& \text { Domains } \\
& \begin{array}{l}
11-20 \\
\geq 21 \\
\text { Teacher garden training } \\
\text { Missing } \\
\text { No } \\
\text { Yes }
\end{array}
\end{aligned}
$$

Frequencies, n (\%)

$11(10)$

$6(6)$

$27(25)$

$74(68)$

GREEN indicates garden resources, education, and environment nexus.

reflective of only the teachers that completed the surveys and maybe an underestimation. School and district administrators can encourage more teachers to take their classes out to the garden to increase student usage.

Having adequate garden training for teachers was also essential for successful and sustainable school garden programs. Similarly, Burt et $\mathrm{al}^{14}$ reported that providing time for staff garden training was essential to increase school garden use. It is unreasonable to expect a dedication to the gardening program by teachers who may have no background in gardening and no district and/or administration directive to use the garden. Teachers are historically overworked and have very tight schedules. ${ }^{25}$
They need to receive training on how the garden can be used as a tool in their existing curriculum. A survey of $\geq 1,000$ Virginia teachers indicated that $88 \%$ of teachers had a high level of interest in using gardening in the classroom but felt they needed supplemental training to integrate gardening into their teaching. ${ }^{26}$ Gardens provide a departure from traditional classroom learning, which provides an alternative way for students to learn critical skills, allowing students to have a more experiential and kinesthetic lesson.

Having a thriving garden was also linked to having access to a gardenbased curriculum. Similarly, findings from Burt et $\mathrm{al}^{14}$ suggest that garden curriculum be integrated into the daily school curriculum to generate a positive student learning experience in the garden. There are numerous available national garden curricula that are either free or available at low-cost to schools, including Junior Master Gardener, ${ }^{27}$ LifeLab, ${ }^{28}$ Edible Schoolyard, ${ }^{29}$ Slow Food USA, ${ }^{30}$ and many more. However, most of the existing curricular resources are not evidence-based and focus more on math, science, and horticultural knowledge than nutrition and health. Given that 40 states, $78 \%$ of the nation, require nutrition education be taught in public schools to all students, ${ }^{8}$ school gardens may play a vital role in fulfilling this nutrition education mandate. Garden-based curricula are often mapped on school standards for math and science, but they also provide an ideal opportunity to infuse required nutrition education into the classroom.

Garden leadership also predicted the sustainability of school gardens. Similarly, Burt et al ${ }^{12}$ suggested that forming garden committees is 1 way to bring school stakeholders and volunteers together in their efforts to support their school garden. Garden committees can consist of teachers, parents, and even students serving

\section{Teacher Perceived Barriers}

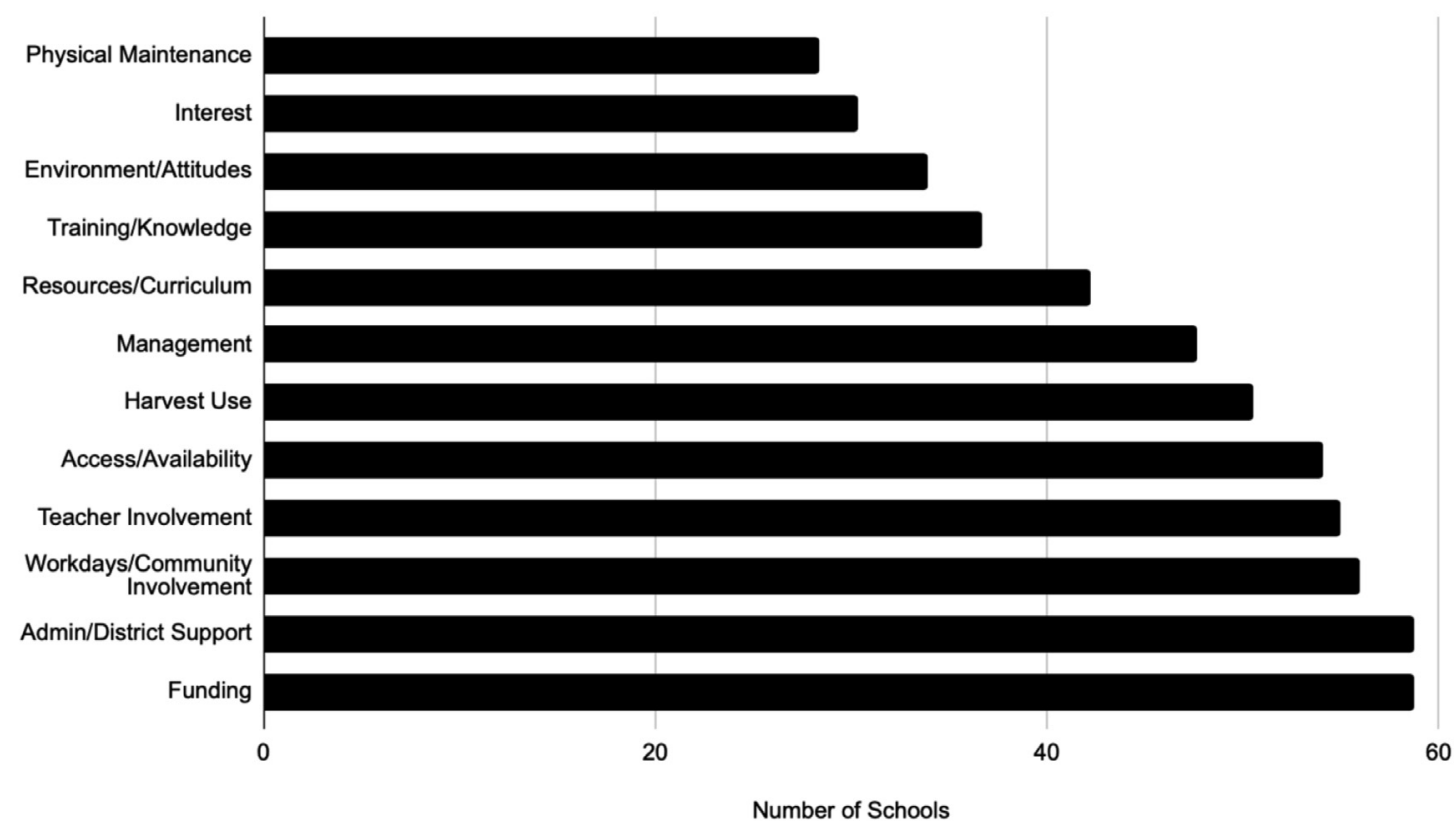

Figure 1. Frequencies of barriers to sustaining a garden reported by teachers. 


\section{Administrator Perceived Barriers}

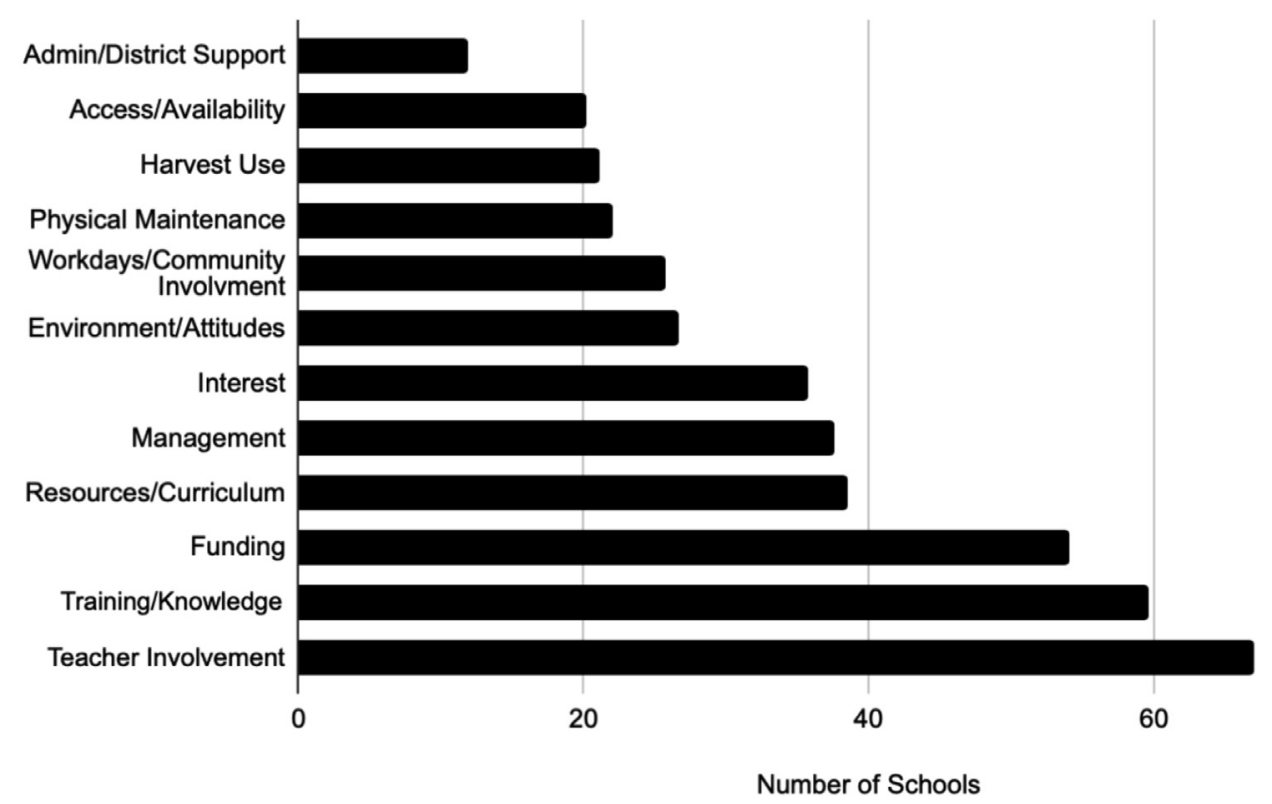

Figure 2. Frequencies of barriers to sustaining a garden reported by administrators.

on the committee. Garden committees can identify when problems exist with school gardens and also assist with programming. Garden committees assist in resolving maintenance issues, coordinating training, encouraging teacher involvement, coordinating garden schedules, communicating around garden activities and harvest, hosting garden events, fundraising, and more. Garden committees can also play the critical role of delegating garden responsibilities among members, making it less likely that a garden will decline if its upkeep is tied to 1 champion.

Adequate funding is another best practice to having a thriving garden; however, what constitutes adequate funding is unclear. Although the current survey asked about annual funding for gardens, the majority of teachers and administrators did not know the actual amount of funding, but the range reported was from $\$ 1$ to $\$ 2,500$ per year. There are numerous grants available to build school gardens but fewer funding mechanisms to help schools sustain their existing school garden. Similarly, Burt et $\mathrm{al}^{14}$ identified lack of funding as a top barrier to school gardens on the East coast, and there was a general lack of awareness of funding sources among respondents. To date, there are a number of grant mechanisms that support garden builds and physical enhancements (such as Whole Food Foundation and Big Green), ${ }^{31,32}$ but fewer funding mechanisms are available that support staff, programming, and resources around sustaining school gardens.

Finally, community partnership was associated with having thriving school gardens. Similarly, the Portland report showed that having enthusiast volunteers from the community was invaluable to the success of the school gardens, and at least two-thirds of schools surveyed in that report had at least 1 partnership. ${ }^{20}$ This report also showed that low-income compared with highincome schools leaned heavily on community partnerships for curricula, funding, and staffing. ${ }^{20}$ Burt et $\mathrm{al}^{14}$ findings showed that engaging the community outside of the school was difficult because family and community members were perceived as too busy to be involved. For-profit, community and/or nonprofits organizations can play a key role in helping with workdays and physical maintenance of the garden, but they can also help with programming. A consistent theme is that the existence and availability of community partners is not well known to schools. Respondents from the Burt et $\mathrm{al}^{14}$ study discussed that there were communication barriers related to reaching community members, lack of a forum to do so, and language barriers.

There are several limitations of this study to consider. Consistently throughout this study, respondents answered survey questions as unknown, or they failed to answer the questions at all. Given that the teachers surveyed were those who used the garden the most, the large number of unknown responses was surprising. However, data were determined to be missing at random. These results may reflect the haphazard way school gardens are managed and/or the lack of communication around school gardens. Often 1 group manages the budget of a school garden, such as the Parent Teacher Association, and other stakeholders are unaware of the specifics of funding. Close to $20 \%$ of stakeholders surveyed did not know if they even had a garden coordinator, which shows that school garden leadership is not well defined or centralized at schools and warrants improvements. Another limitation is 


\section{Table 4. Variables Within Each Domain Predicting a Thriving Garden}

\section{Domains}

Domain A: resources and support

Garden funded

No

Yes

Community partner use

No

Yes

Garden coordinator

None

Yes

Paid

Garden committee

None

Yes

Administrator/district support

None

Yes

Domain B: physical care

Perceptions of garden condition

Disrepair or unmaintained

Somewhat maintained

Well-maintained

Physical observation of the garden condition

Disrepair or unmaintained

Somewhat maintained

Well-maintained

Workdays

None

Yes

Sum of harvest usage

None or unknown

1

2

$\geq 3$

Domain C: student engagement

Garden curriculum available

None

Yes

Student yearly usage, number of students

$1-50$

$51-100$

$101-200$

$\geq 201$

Teaching amount, times per y

$1-2$

$1-2$

Monthly

Weekly

No. of core classes that used garden

None

1

2

3

$\geq 4$

No. of noncore classes that used the garden

None $\beta$

$95 \% \mathrm{Cl}$

Ref

3.51

Ref

3.01

Ref

2.77

6.00

Ref

4.67

Ref

11.98

Ref

2.81

3.27

Ref

1.03

2.14

Ref

0.15

Ref

2.00

3.27

3.81

Ref

4.84

Ref

0.81

4.53

11.30

Ref

0.17

0.13

1.27

Ref

0.65

6.88

6.11

Ref
$1.20-10.26$

0.02

$1.16-7.83$

0.02

$0.55-13.91$

0.212

$0.92-39.19$

0.06

0.02

0.02

$1.53-9.34$

0.35

$0.33-24.04$

$0.36-30.10$

0.30

$0.23-4.53$

0.97

0.54-8.51

0.28

$0.18-1.21$

0.08

$0.32-12.33$

0.46

$0.62-17.39$

0.16

$0.73-19.28$

0.11

0.003

$1.73-13.56$

$0.16-4.18$

1.02-20.19

0.80

0.05

$2.39-53.75$

0.002

0.01-3.89

$0.01-3.08$

0.27

0.11-14.95

0.21

0.85

$0.04-11.45$

0.77

0.67-70.82

0.11

$0.60-62.23$

0.13

$0.47-33.87$

0.21 
Table 4. (Continued)

\begin{tabular}{|c|c|c|c|}
\hline Domains & $\beta$ & $95 \% \mathrm{Cl}$ & $\boldsymbol{P}$ \\
\hline 1 & 1.64 & $0.29-9.29$ & 0.57 \\
\hline 2 & 2.19 & $0.43-11.27$ & 0.35 \\
\hline$\geq 3$ & 3.83 & $0.99-14.84$ & 0.05 \\
\hline \multicolumn{4}{|c|}{ Domain D: school community } \\
\hline \multicolumn{4}{|c|}{ Volunteers } \\
\hline None & Ref & & \\
\hline Yes & 0.94 & $0.35-2.55$ & 0.90 \\
\hline \multicolumn{4}{|c|}{ Hours volunteers worked, h/y } \\
\hline None & Ref & & \\
\hline $1-10$ & 0.47 & $0.16-1.28$ & 0.17 \\
\hline $11-20$ & 0.48 & $0.09-2.58$ & 0.39 \\
\hline$\geq 21$ & 1.08 & $0.17-6.75$ & 0.93 \\
\hline \multicolumn{4}{|c|}{ Teacher garden training } \\
\hline None & Ref & & \\
\hline Yes & 4.88 & $1.04-22.95$ & 0.05 \\
\hline
\end{tabular}

$\mathrm{Cl}$ indicates confidence interval; Ref, reference.

Note: Regression analyses were run to examine how each variable predicts having a thriving garden.

that reliability testing was not performed on this survey, and the results of this study may not be consistent and/or repeatable in other studies. Another limitation is that schools were given no prior notice of the physical observation of the garden, limiting the garden to 1 point in time. As the garden may not have been in its typical condition, this may not be the most effective way to classify garden status. The use of a convenience sample is also a limitation; however, it is widely used in studies like this, in which a particular group of school garden stakeholders was asked to answer survey questions. Nonetheless, the findings from this nonrepresentative sample limit generalizability.

\section{IMPLICATIONS FOR RESEARCH AND PRACTICE}

The purpose of this study was to identify school garden attributes and practices that most strongly contribute to garden use and sustainability and translate them into recommendations for improving garden-based nutrition education. Having administrator and district support was key to the success and sustainability of school gardens. These findings suggest that school and district administrators need to support teacher training, offer an integrated garden curriculum in daily lessons, facilitate student usage of school gardens, form and incentivize garden leadership committees, help secure funding, and establish links between community partners and volunteers for the school garden. There is a need for more district-level funding to support school gardens, as well as city, state, and federal grants to provide support for school garden programs. Community and nonprofit organizations providing funding opportunities to support school gardens are also needed. School and district administrators can encourage the use of the garden by either approving usage of an existing garden-based curriculum as part of their available lesson plans or working with their district curriculum department to create options in their existing lesson plans to use in the garden. Currently, there is not a central site that identifies location-specific funding sources, location-specific teacher garden resources, or garden-based curriculum for a specific grade and content area. Creating better channels and platforms to disseminate information about funding announcements, garden-based curriculum, and available garden resources within schools and with communities is warranted. Provision of garden-based training to teachers is also needed to facilitate teachers being confident and competent in teaching in outdoor spaces.
There is a need to connect small businesses, community, and nonprofit groups with schools and school districts and a need to establish easier connections and communication platforms for this type of partnership.

Supporting school gardens can lead to a more hands-on, multifaceted educational environment that would enhance and foster nutrition behavior experiences in children of all ages nationwide.

\section{ACKNOWLEDGMENTS}

This work was supported by the City of Austin Office of Sustainability. The authors would like to thank all school stakeholders (ie, administrators, teachers, and staff) for participating in this study. The authors would also like to thank Bianca Bidiuc Peterson and Sari Albornoz from the Sustainable Food Center for collaborating with us on this project, the Home Depot for their garden supply donations and attendance at all school garden builds, and all of the University of Texas at Austin undergraduate students for all their hard work helping us collect the data.

\section{SUPPLEMENTARY DATA}

Supplementary data related to this article can be found at https://doi. org/10.1016/j.jneb.2021.02.011. 


\section{REFERENCES}

1. Davis JN, Spaniol MR, Somerset S. Sustenance and sustainability: maximizing the impact of school gardens on health outcomes. Public Health Nutr. 2015;18:2358-2367.

2. Parmer SM, Salisbury-Glennon J, Shannon D, Struempler B. School gardens: an experiential learning approach for a nutrition education program to increase fruit and vegetable knowledge, preference, and consumption among second-grade students. J Nutr Educ Behav. 2009;41:212-217.

3. McAleese JD, Rankin LL. Gardenbased nutrition education affects fruit and vegetable consumption in sixthgrade adolescents. J Am Diet Assoc. 2007;107:662-665.

4. Wells NM, Meyers BM, Todd LE, et al. The carry-over effects of school gardens on fruit and vegetable availability at home: a randomized controlled trial with low-income elementary schools. Prev Med. 2018;112:152-159.

5. Evans A, Ranjit N, Rutledge R, et al. Exposure to multiple components of a garden-based intervention for middle school students increases fruit and vegetable consumption.. Health Promot Pract. 2012;13:608-616.

6. Wang MC, Rauzon S, Studer N, et al. Exposure to a comprehensive school intervention increases vegetable consumption. J Adolesc Health. 2010;47:7482.

7. US Census Bureau. Current population survey data on school enrollment. https://www.census.gov/topics/education/school-enrollment.html. Accessed November 20, 2020.

8. Centers for Disease Control and Prevention. National Health Education Standards. https://www.cdc.gov/ healthyschools/sher/standards/index. htm. November 20, 2020.

9. Texas Statutes. Education code. Chapter 38. Health and safety. http://www. statutes.legis.state.tx.us/SOTWDocs/ ED/htm/ED.38.htm. November 20, 2020

10. Gatto NM, Martinez LC, Spruijt-Metz D, Davis JN. LA sprouts randomized controlled nutrition, cooking and gardening programme reduces obesity and metabolic risk in Hispanic/Latino youth. Pediatr Obes. 2017;12:28-37.

11. Davis JN, Perez A, Asigbee FM, et al. School-based gardening, cooking and nutrition intervention increased vegetable intake but did not reduce BMI: Texas sprouts - a cluster randomized controlled trial. Int J Behav Nutr Phys Act. 2021;18:18.

12. Burt KG, Luesse HB, Rakoff J, Ventura A, Burgermaster M. School gardens in the United States: current barriers to integration and sustainability. Am J Public Health. 2018;108:1543-1549.

13. Loftus L, Spaulding AD, Steffen R, Kopsell D, Nnakwe N. Determining barriers to use of edible school gardens in Illinois. $\mathrm{J} \mathrm{Am}$ Coll Nutr. 2017;36:507-513.

14. Burt KG, Burgermaster M, Jacquez R. Predictors of school garden integration: factors critical to gardening success in New York City. Health Educ Behav. 2018;45:849-854.

15. Ratcliffe MM. A sample theory-based logic model to improve program development, implementation, and sustainability of Farm to School programs. Child Obes. 2012;8:315-322.

16. Hazzard EL, Moreno E, Beall DL. Zidenberg-Cherr S. Best practices models for implementing, sustaining, and using instructional school gardens in California. J Nutr Educ Behav. 2011;43:409413.

17. Turner L, Eliason M, Sandoval A, Chaloupka FJ. Increasing prevalence of US elementary school gardens, but disparities reduce opportunities for disadvantaged students. J Sch Health. 2016;86:906-912.

18. Turner L, Leider J, Piekarz E, et al. Facilitating fresh: state laws supporting school gardens are associated with use of garden-grown produce in school nutrition services programs. J Nutr Educ Behav. 2017;49: 481-489.e1.

19. Burns H, Miller W. The Learning Gardens Laboratory: teaching sustainability and developing sustainable food systems through unique partnerships. J Agric Food Syst Commun Dev. 2012;2:69-78.
20. Garwood A, Wasserstrom P, Logan S, Steeves, S. Portland School Garden Assessment. Growing Gardens; 2016. http:// www.growing-gardens.org/wp-content/uploads/2017/04/SchoolGardenSurveyReportFinal.pdf. Accessed November 20, 2020.

21. Ozer EJ. The effects of school gardens on students and schools: conceptualization and considerations for maximizing healthy development. Health Educ Behav. 2007;34:846-863.

22. Burt KG, Koch P, Contento I. Development of the GREEN (garden resources, education, and environment nexus) tool: an evidence-based model for school garden integration. J Acad Nutr Diet. 2017;117: 1517-1527.e4.

23. Streiner D, Norman G. Health Measurement Scales: A Practical Guide to Their Development and Use. 4th ed. Oxford University Press; 2008.

24. McDowell I. Measuring Health: A Guide to Rating Scales and Questionnaires. 3rd ed. Oxford University Press; 2006.

25. Marzano RJ, Heflebower T. Teaching and Assessing 21st Century Skills. Bloomington, IN: Marzano Research Laboratory; 2012.

26. Dobbs K, Relf D, McDaniel A. Survey on the needs of elementary education teachers to enhance the use of horticulture or gardening in the classroom. Hort Technology. 1998;8:370-373.

27. Junior Master Gardener. Curriculum. https://jmgkids.us/curriculum/. Accessed November 20, 2020.

28. Life Lab. About Life Lab. https://www. lifelab.org/about/. Accessed January 20, 2020.

29. The Edible Schoolyard Project. https:// edibleschoolyard.org. Accessed November 20, 2020.

30. Slow Food USA. https://slowfoodusa. org. Accessed November 20, 2020.

31. KidsGardening. Grant opportunities for school and youth garden programs. https://kidsgardening.org/grant-opportunities/. Accessed February 20, 2021.

32. Whole Kids Foundation. School garden resources. https://www.wholekidsfoundation.org/school-gardens. Accessed February 20, 2021. 